\section{D) Check for updates}

Cite this: Analyst, 2020, 145, 7279

\title{
Evaluation of swabs from 15 commercially available oral fluid sample collection devices for the analysis of commonly abused substances: doping agents and drugs of abuse $\dagger$
}

\begin{abstract}
Łukasz Sobczak (D) \$ and Krzysztof Goryński (D)*
Oral fluid testing is steadily building its position as a valuable complement or alternative to plasma and urine analyses in everyday laboratory practice. However, the great significance of the sample collection process in the attainment of representative results is not always paralleled by the attention given to its informed selection. Few evaluations of commercially available sample collection devices have been published until now, and the current work intends to fill this gap by presenting an evaluation of swabs from 15 different devices for the analysis of 49 popular drugs. Swabs, derived from sample collection devices, were used to collect a drug-fortified mixture. Then, swab-retrieved samples were subjected to instrumental analysis with the high-performance liquid chromatography coupled with tandem mass spectrometry method. Results within the $80-120 \%$ range were considered to have no significant impact on analyte concentration (thus satisfactory) and were observed in $44.1 \%$ of all results. Out of the 15 evaluated swabs, 7 provided results in the aforementioned range for more than half of the substances under study. The possibility of matrix effects originating from swab materials was also investigated. The selection of an appropriate oral fluid sample collection method plays a critical role in the success of the analytical procedure, a fact that is well-illustrated by the tremendous differences between analyte concentrations observed in this research. Perhaps, the tedious labour of improving sample preparation and analysis methods already in-use could be spared if only greater emphasis were to be put on the improvement and better selection of suitable solutions for oral fluid collection.
\end{abstract}

Received 9th July 2020 Accepted 12th August 2020 DOI: 10.1039/d0an01379j rsc.li/analyst are present in plasma $(\mathrm{pH}=7.35-7.45)$ as neutral molecules, but ionize after diffusion to more acidic oral fluid $(\mathrm{pH}=$ 6.2-7.4), subsequently becoming no longer involved in the equilibrium-driven process of passive diffusion, and thus remaining trapped in oral fluid at increasing total concentrations. $^{2}$

Oral fluid is an already well-established bioanalytical specimen alternative or complementary to plasma or urine in the fields of forensics and therapeutic drug monitoring (TDM), as well as for examination procedures related to driving under the influence of drugs and workplace testing. ${ }^{5-9}$ The use of oral fluid in doping control is also an increasing trend. ${ }^{3,10,11}$

The provision and collection of oral fluid specimens is convenient, non-invasive, and preferred over blood or urine donation according to the results of several survey-based studies. $^{12-14}$ Oral fluid samples can be collected by passive drool (or simply spitting) into plastic tubes/vials, via rinsing with a special extraction solution (as in the saliva collection system device from Greiner Bio-One International), or collected with absorptive materials. The use of commercially available devices made of absorptive materials is more popular
Bioanalysis Scientific Group, Faculty of Pharmacy, Collegium Medicum in Bydgoszcz at Nicolaus Copernicus University in Toruń, dr. Antoniego Jurasza 2 street, 85-089 Bydgoszcz, Poland. E-mail: gorynski@cm.umk.pl

$\dagger$ Electronic supplementary information (ESI) available: A - analysed substances; B - complete results. See DOI: 10.1039/d0an01379j

$\$$ These authors contributed equally. 
with donors and their supervisors, being praised as more hygienic and easier to handle. ${ }^{6}$ However, passive drool remains unparalleled in terms of sample quality due to it carrying the lowest number of factors negatively affecting the collected oral fluid and therefore providing the truest results among the described collection methods.

However, despite possible drawbacks such as analyte loss due to unspecific binding to collection swabs, swab handle and transport tube materials (this issue is especially important for $\Delta^{9}$-tetrahydrocannabinol (THC) analysis ${ }^{15-17}$ ), or contaminants originating from collection device elements, the use of absorptive devices is currently predominant in oral fluid sample collection. Rarely are such commercial products validated for specific analyte collection (usually an endogenous hormone - e.g. Salivette ${ }^{\circledR}$ Cortisol from Sarstedt), and reports on device performance for exogenous substance collection are scarce and limited only to the most popular drugs. ${ }^{18,19}$ Such a situation hinders the development of oral fluid testing in general. To address this uncertainty, several evaluations of commercial products have been already published in scientific literature, but these are unfortunately limited only to a single or few devices at a time. ${ }^{17,20-26}$ Research by Langel et al. ${ }^{27}$ (comparing 9 different devices) stands out as perhaps the most comprehensive work to date. Regrettably, more than a decade after its publication in 2008, only 5 out of 9 tested devices still remain available on the market, decreasing its usefulness for contemporary researchers. Therefore, the herein presented evaluation of swabs from 15 various devices for the analysis of 49 commonly abused substances could be of substantial aid in the selection of an appropriate collection device for a given drug or class of drugs and may help avoid numerous difficulties at the very first step of the analytical process - sample collection. This may play a significant role in the successful analysis of potent drugs present in biological matrices only at trace amounts.

\section{Experimental section}

\section{Substances analysed}

A total of 49 commonly abused substances (drugs of abuse and doping agents) were selected for a comparison of recoveries from swabs based on the latest report of The European Monitoring Centre for Drugs and Drug Addiction (EMCDDA), ${ }^{28}$ and laboratory testing figures of The World AntiDoping Agency (WADA). ${ }^{29}$ Among the chosen compounds, 21 are considered recreational drugs and 43 are substances banned in sports (from all classes listed in WADA's Prohibited List $^{30}$ ) - see Table A1 in ESI A $\uparrow$ for a detailed list. The selected substances include 6 most abused drugs in Europe: cannabis (as THC and its long-lasting metabolite 11-nor-9-carboxy- $\Delta^{9}$ tetrahydrocannabinol (THC-COOH)), cocaine, heroin, amphetamine, methamphetamine, and ecstasy (3,4-methylenedioxymethamphetamine, MDMA). ${ }^{28}$ Also, 13 of the 15 most frequently detected doping agents were analysed: clenbuterol (with 320 reported offences in 2018 according to the latest annual report by the WADA), stanozolol (235), furosemide (172), nandrolone (150), THC-COOH (141), methandienone (131), hydrochlorothiazide (127), meldonium (111), amphetamine (95), and methylphenidate (91), as well as boldenone, cocaine, and terbutaline (87 offences each). ${ }^{29}$

\section{Sample collection devices}

A total of 15 different swabs from oral fluid collection devices from 10 different manufacturers were compared during experiments (see Fig. 1). Their characteristics based on available product information (instructions and leaflets) are summarized in Table 1. It should be noted that this work evaluated only the swabs, and as such it may be less relevant in the case of 5 devices, where the processed sample should be placed into an extraction fluid (buffer and/or preservative solution), according to the recommended protocol, if the device is used as recommended. These particular devices are the Oasis Diagnostics ${ }^{\circledR} \mathrm{Accu} \cdot \mathrm{SAL} \mathrm{L}^{\mathrm{TM}}$, OraSure Technologies Intercept ${ }^{\circledR}$ i2 $2^{\mathrm{TM}}$, Thermo Scientific ${ }^{\mathrm{TM}}$ Oral-Eze ${ }^{\mathrm{TM}}$, StatSure ${ }^{\mathrm{TM}}$ Saliva Sampler ${ }^{\mathrm{TM}}$, and Immunalysis ${ }^{\mathrm{TM}}$ Quantisal ${ }^{\circledR}$.

\section{HPLC-MS/MS analysis}

All samples were analysed on a Shimadzu LCMS-8060 triple quadrupole system. Samples ( $8 \mu \mathrm{L}$ injection volume) were separated on an Agilent InfinityLab Poroshell 120 EC-C18 column

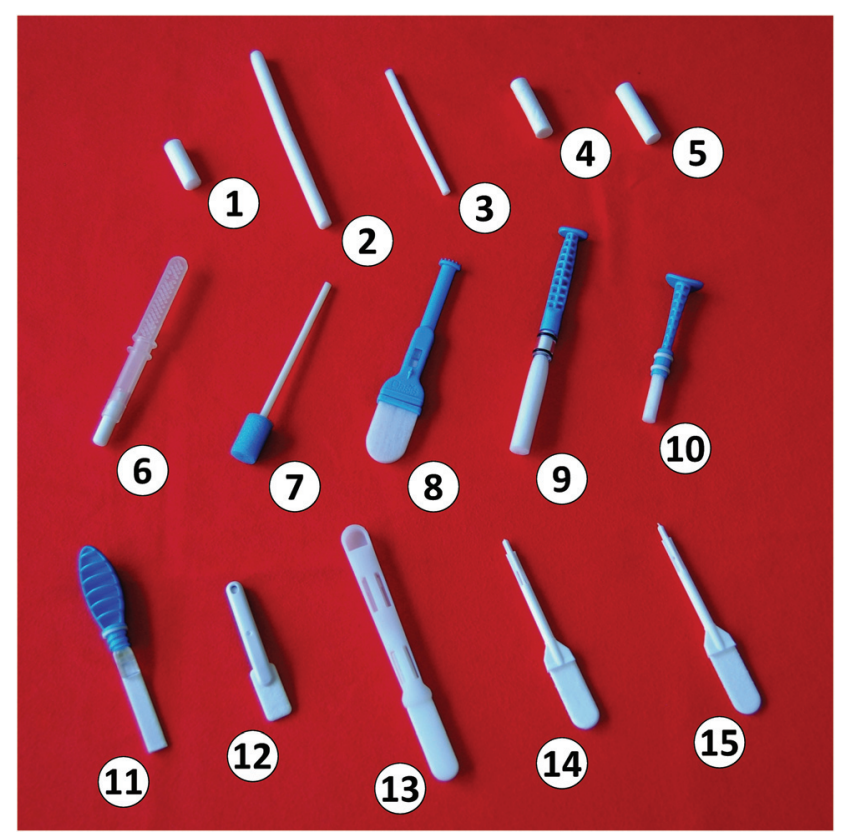

Fig. 1 Oral fluid collection devices. Devices presented: 1 Salimetrics ${ }^{\circledR}$ SalivaBio Oral Swab; 2 - Porex ${ }^{\circledR}$ Saliva Collection Swab (type 1); 3 - Porex ${ }^{\circledR}$ Saliva Collection Swab (type II); 4 - Sarstedt Salivette ${ }^{\circledR} ; 5$ - Sarstedt Salivette ${ }^{\circledR}$ Cortisol; 6 - Dräger DCD ${ }^{\text {TM }}$ 5000; 7 - Malvern Medical Developments Oracol; 8 - Oasis Diagnostics ${ }^{\circledR}$ Versi.SAL ${ }^{\circledR} ; 9$ - Oasis Diagnostics ${ }^{\circledR}$ Super.SALTM; 10 - Oasis Diagnostics ${ }^{\circledR}$ Micro.SALTM; 11 - Oasis Diagnostics ${ }^{\circledR}$ Accu.SAL ${ }^{\mathrm{TM}} ; 12$ OraSure Technologies Intercept ${ }^{\circledR} \mathrm{i}^{\mathrm{TM}} ; 13$ - Thermo Scientific ${ }^{\mathrm{TM}}$ OralEze $^{\mathrm{TM}} ; 14$ - StatSure ${ }^{\mathrm{TM}}$ Saliva Sampler ${ }^{\mathrm{TM}} ; 15$ - Immunalysis ${ }^{\mathrm{TM}}$ Quantisal ${ }^{\circledR}$ 


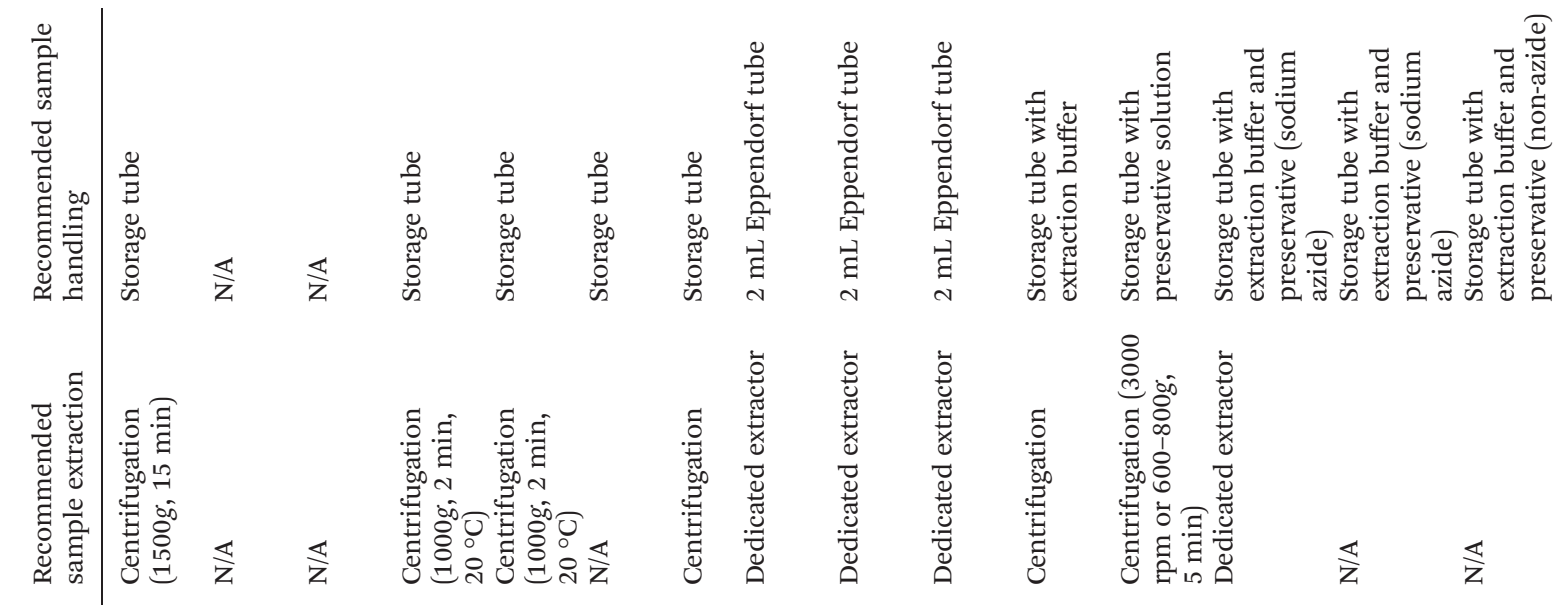

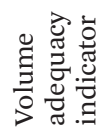

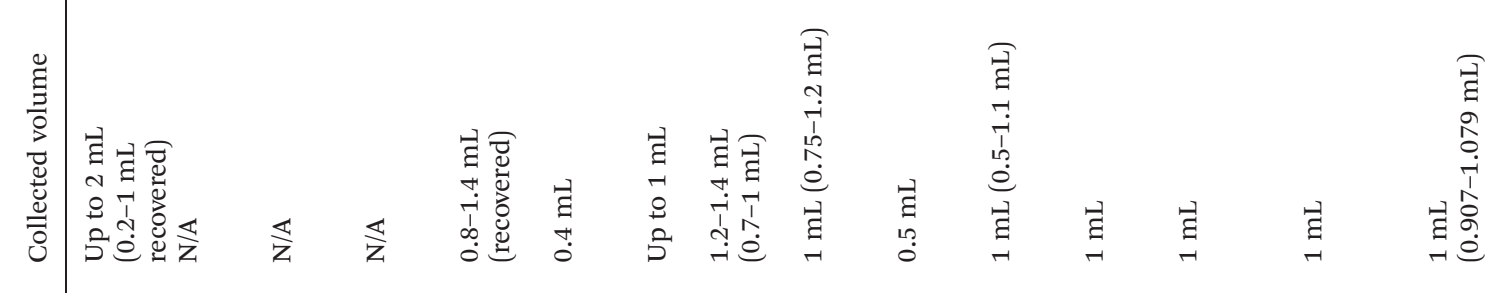

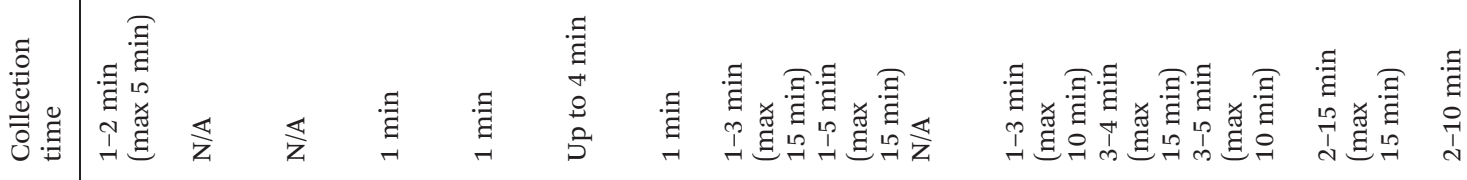

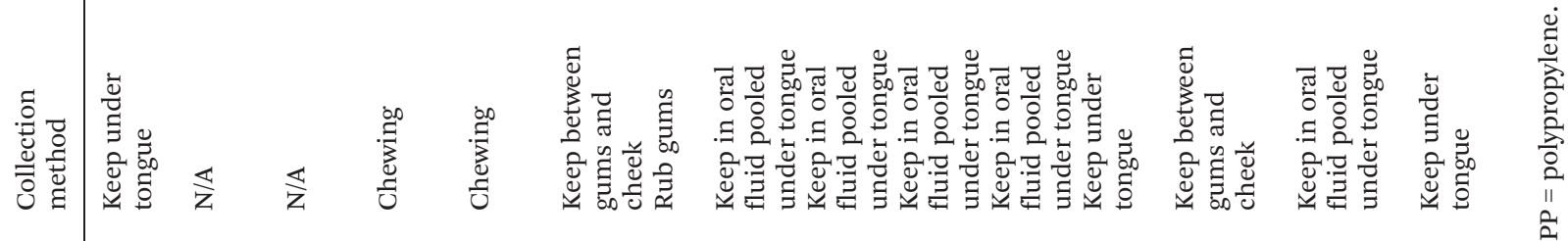

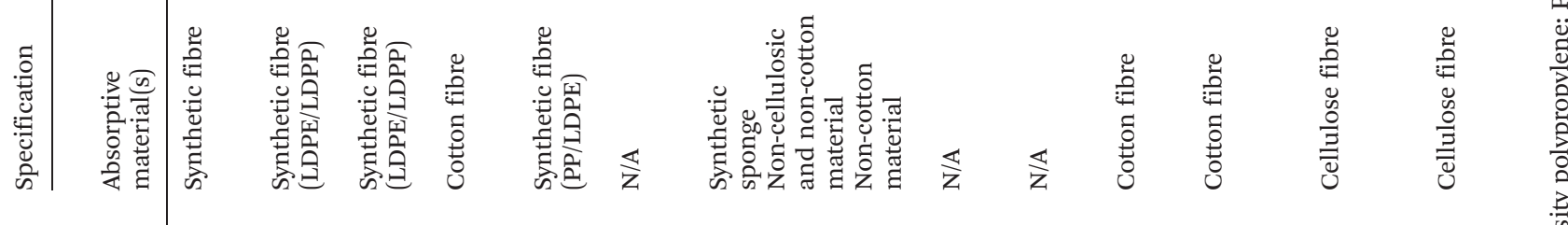

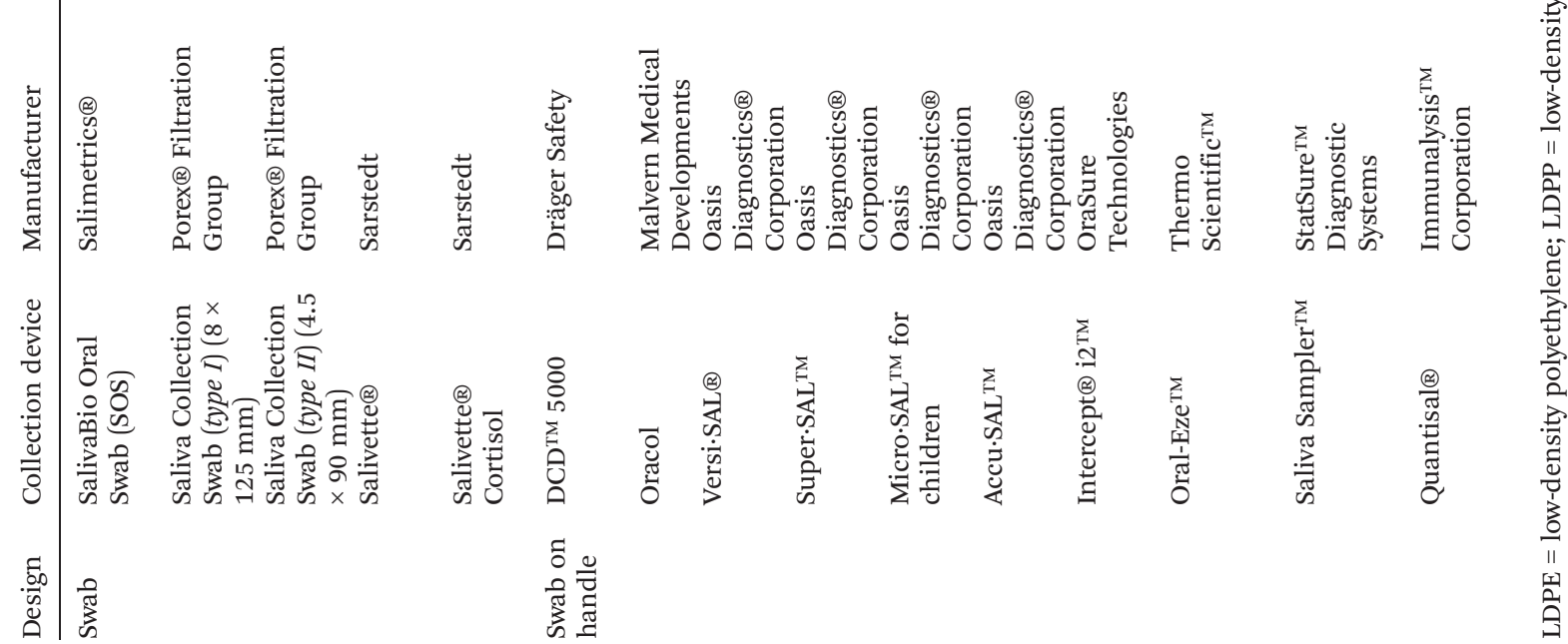


$(3 \times 100 \mathrm{~mm}, 2.7 \mu \mathrm{m})$ with a matching Agilent InfinityLab Poroshell 120 EC-C18 guard column $(3 \times 5 \mathrm{~mm}, 2.7 \mu \mathrm{m})$, using gradient elution in reversed-phase mode. Column oven temperature was set at $25.0{ }^{\circ} \mathrm{C}$. Phase A consisted of LC-MS grade water (LiChrosolv®, Merck) with $0.1 \%$ formic acid (Optima ${ }^{\mathrm{TM}}$ LC/MS, Fisher Chemical), and phase B consisted of LC-MS grade acetonitrile (CHROMASOLV ${ }^{\mathrm{TM}}$, Honeywell) with $0.1 \%$ formic acid (Optima ${ }^{\mathrm{TM}}$ LC/MS, Fisher Chemical). Gradient starting conditions were $10 \%$ phase B (maintained for $0.5 \mathrm{~min}$ ), followed by a linear increase of phase $\mathrm{B}$ concentration to $100 \%$ (for $25.5 \mathrm{~min}$ ), hold at $100 \%$ phase $\mathrm{B}$ (for $3 \mathrm{~min}$ ) and column re-equilibration with $10 \%$ phase B (6 min). Total running time was $35 \mathrm{~min}$ per sample. The total flow rate

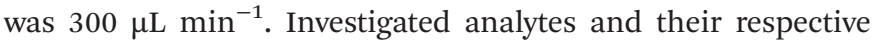
monitored $\mathrm{m} / \mathrm{z}$ ratios are listed in Table A2 in ESI A. $\dagger$

\section{Experimental design}

In order to obtain as reliable results as possible, LC-MS grade water was used to mimic oral fluid in a preparation of testing solution spiked with the analytes. By doing so, widely known factors that would have negative impact on data quality, if oral fluid was to be tested instead of ultrapure water, were omitted. For example, irreproducibility of oral fluid could be an outcome of circadian secretion rhythms of endogenous hormones, separation of oral fluid emulsion (formation of layers with different densities and protein contents ${ }^{31}$ ), bacterial and enzymatic activity, ${ }^{21}$ and sample contamination with the residue of food or mouth hygiene products among other reasons. However, such design of the experiment raises concerns over the relevance of its results in accordance with the actual oral fluid testing. To address these concerns and reassure that the results are reliable, a follow-up experiment involving oral fluid samples was performed to compare recovery values recorded for both matrices, the results of which are presented and discussed in this work.

As a means to enable substance recovery comparisons between various devices under evaluation, unified proceedings were always applied, which sometimes necessitated alterations of the protocols recommended by manufacturers of said devices. Also, only the absorptive parts (swabs) of the devices were used for sampling, without attached handles or dedicated extractors that accompany certain devices for collection from living donors.

\section{Drug recovery}

Drug recoveries from oral fluid collection device swabs were tested by inserting swabs into a spiked mixture with the above specified analytes at individual concentrations of $10 \mathrm{ng} \mathrm{mL} \mathrm{m}^{-1}$. The first step was carried out in $15 \mathrm{~mL}$ Falcon type plastic tubes. Swabs were fully immersed in the mixture for $60 \mathrm{~min}$ to allow the analytes to bind to the absorption materials. Next, each swab was removed with single-use nitrile gloves and squeezed with a disposable needle-less plastic syringe (5 or $10 \mathrm{~mL}$ capacity, depending on swab size) into a $2 \mathrm{~mL}$ Eppendorf plastic tube. However due to the stiff structure of Dräger DCD ${ }^{\mathrm{TM}} 5000$ swabs it was not possible to squeeze them with a syringe barrel, and instead centrifugation in special tubes with pre-cut holes in their bottom was incorporated. Centrifuged samples were then transferred to the $2 \mathrm{~mL}$ Eppendorf tubes. All of the $2 \mathrm{~mL}$ tubes were centrifuged $\left(1500 \mathrm{~g}, 3 \mathrm{~min}, 4^{\circ} \mathrm{C}\right)$ to force sedimentation of particulate residues originating from the swab (the formation of which was already reported in the literature ${ }^{23}$ ). The supernatant was then transferred into silanized $2 \mathrm{~mL}$ HPLC vials with PTFE-bonded/ silanized caps. Each swab type was tested in quadruplicate. Drug recoveries were calculated as mean values relative to the mean values $(n=4)$ of the reference sample (portion of the drug-spiked mixture, measured twice before and twice after the samples of each swab type).

\section{Non-specific binding of drugs to laboratory plastics}

While prepared samples were kept in silanized vials in order to reduce drug losses related to non-specific binding, the experimental proceedings required the use of multiple laboratory plastics (see the Drug recovery paragraph). Given this, nonspecific binding of the analytes to $15 \mathrm{~mL}$ Falcon tubes, 5 or $10 \mathrm{~mL}$ syringes, and $2 \mathrm{~mL}$ Eppendorf tubes was assessed by incubating the drug mixture inside plastics for $60 \mathrm{~min}$, and then measuring such samples against reference samples. Each experiment was repeated 4 times.

\section{Matrix effect assessment}

In order to test the hypothesis that some of the tested swabs from oral fluid collection devices could contaminate samples, which could in turn affect MS/MS detection, an additional experiment was performed. Drug-free water was collected with each swab and subsequently recovered from swabs using the same protocol described in the Drug recovery paragraph. Samples of matrices retrieved from the sample collection device swabs, as well as the neat matrix, were then spiked with the drug mixture (each substance present in the concentration of $10 \mathrm{ng} \mathrm{mL}{ }^{-1}$ ) and subjected to instrumental analysis. Results were calculated as signals measured from the spiked matrix collected with swabs relative to signals from the spiked neat matrix. Each type of swab was tested in triplicate.

\section{Eligibility of testing recovery from swabs with ultrapure water}

Oral fluid (negative for all the analytes) provided by two volunteers was spiked with 43 drugs at a concentration of $10 \mathrm{ng}$ $\mathrm{mL}^{-1}$ each. Informed consent was obtained from the participants prior to sampling, and all experiments were performed in compliance with applicable policies and guidelines (permission to conduct experiments with oral fluid was issued by the Bioethics Committee of Collegium Medicum in Bydgoszcz at Nicolaus Copernicus University in Torun, permission number KB 651/2018). Six drugs used for previous experiments were excluded from this test, due to the insufficient recovery of the extraction method (hydrochlorothiazide and psilocybin), or intense matrix effect causing the previously tested recovery values to exceed $150 \%$ (bisoprolol, meldonium, methylphenidate, and phencyclidine). 
Drug-fortified oral fluid samples were collected with Sarstedt Salivette ${ }^{\circledR}$ swabs and handled with the same protocol as described in the Drug recovery paragraph. Prior to instrumental analysis, the analytes were extracted from oral fluid recovered from the swabs with the use of C18 SPME LC fiber probes (Supelco®). The following 6-step extraction protocol was used: I - preconditioning \#1 (1.5 mL methanol/water (90/ 10, v/v), $60 \mathrm{~min}, 850 \mathrm{rpm}$ agitation); II - preconditioning \#2 (1.5 mL methanol/water (10/90, v/v), $60 \mathrm{~min}, 850 \mathrm{rpm}$ agitation); III - rinse \#1 (1.5 mL of water, $2 \mathrm{~s}$, no agitation); IV extraction (700 $\mu \mathrm{L}$ of oral fluid, $60 \mathrm{~min}, 850 \mathrm{rpm}$ agitation); V rinse \#2 (1.5 mL of water, $2 \mathrm{~s}$, no agitation); VI - desorption (150 $\mu \mathrm{L}$ acetonitrile/water/formic acid (80/19.9/0.1, v/v), $60 \mathrm{~min}, 850 \mathrm{rpm}$ agitation). The injection volume was $1.2 \mu \mathrm{L}$ $(4 \times 0.3 \mu \mathrm{L})$ in POISe injection. Swabs were tested in triplicate, and the recovery values were compared with the ones recorded after the use of ultrapure water as the matrix.

\section{Results and discussion}

The detection method was linear in the anticipated concentration range of 1-10 $\mathrm{ng} \mathrm{mL}^{-1}$. Coefficient of determination values from 7-point calibration curves for all substances exceeded $R^{2}=0.99$, both without and with $1 /$ a or $1 / \mathrm{a}^{2}$ weighting applied.

The stability of the tested drugs during the $60 \mathrm{~min}$ sampling period at room temperature and during the period of time in which samples were placed in a refrigerated autosampler (maintained at $4{ }^{\circ} \mathrm{C}$ ) until LC-MS/MS analysis should not influence the results, as all reference samples were stored under exactly the same conditions throughout the entire process.

\section{Drug recovery}

No significant drug losses (recovery values in the $80-120 \%$ range) for the majority of the tested substances were observed for 7 out of the 15 evaluated swabs (full results are presented in Table B2 in ESI B $\dagger$ ). The greatest number of recovery values in such a range (29 out of 49 drugs) was achieved with 3 different swabs: Porex® Saliva Collection Swab (type I), Porex® Saliva Collection Swab (type II), and Dräger DCD ${ }^{\mathrm{TM}}$ 5000. The majority of results were also satisfactory for the Salimetrics ${ }^{\circledR}$ SalivaBio Oral Swab (28/49), StatSure ${ }^{\mathrm{TM}}$ Saliva Sampler ${ }^{\mathrm{TM}}$ (27/49), Immunalysis ${ }^{\mathrm{TM}}$ Quantisal ${ }^{\circledR}$ and Oasis Diagnostics ${ }^{\circledR}$ Accu.SAL ${ }^{\mathrm{TM}}$ (both 25/49). Significant analyte loss (recoveries below $80 \%$ ) for more than half of the tested drugs was observed with 4 swabs. The lowest numbers of undesired results (below 80\%) were observed with Dräger DCD ${ }^{\mathrm{TM}} 5000$ (only 8 out of 49 ) and Porex® Saliva Collection Swab (type II) (9/49).

In terms of the drugs being analysed, anastrozole, betamethasone, nandrolone, and prednisone proved to be the least affected by the collection process, with recoveries in the $80-120 \%$ range for 14 out of the 15 tested swabs. On the other hand, compounds such as LSD, methadone, nebivolol, stano- zolol, and THC could not be recovered by any of the tested swabs in the $80-120 \%$ range. The highest measured values of these drugs were achieved with OraSure Technologies Intercept ${ }^{\circledR} \quad \mathrm{i} 2^{\mathrm{TM}}$ for $\operatorname{LSD} \quad(69.9 \%)$, Oasis Diagnostics ${ }^{\circledR}$ Accu.SAL ${ }^{\mathrm{TM}}$ for methadone $(77.7 \%)$, Oasis Diagnostics ${ }^{\circledR}$ Versi·SAL ${ }^{\circledR}$ for nebivolol (59.9\%) and stanozolol $(77.6 \%)$, and StatSure ${ }^{\mathrm{TM}}$ Saliva Sampler ${ }^{\mathrm{TM}}$ for THC $(17.3 \%)$.

\section{Non-specific binding of drugs to laboratory plastics}

The majority of the tested substances were not affected by non-specific binding to laboratory plastics utilized in this research (detailed results for this experiment are presented in Table B1 in ESI B $\dagger$ ). Cases of recoveries below $80 \%$ of reference sample included phencyclidine, canrenone, and stanozolol loss on the $15 \mathrm{~mL}$ Falcon tubes $(76.1 \%, 62.1 \%$, and $61.8 \%$ recoveries, respectively). With THC-COOH, substance loss was observed on 3 of the 4 tested plastics $(22.4 \%$ recovery from $15 \mathrm{~mL}$ Falcon tubes, $40.3 \%$ from $5 \mathrm{~mL}$ syringes, and $47.7 \%$ from $10 \mathrm{~mL}$ syringes). The greatest decline in concentration was measured for THC $(20.5 \%$ recovery from $15 \mathrm{~mL}$ Falcon tubes, $23.9 \%$ from $5 \mathrm{~mL}$ syringes, $24.5 \%$ from $10 \mathrm{~mL}$ syringes, and $41.3 \%$ from $2 \mathrm{~mL}$ Eppendorf tubes).

All of the affected substances have hydrophobic structures, with $\log P$ values of 2.7 for canrenone, 3.6 for phencyclidine, 4.5 for stanozolol, 6.3 for THC-COOH, and 7.0 for THC (all data according to the PubChem database ${ }^{32}$ ). Non-specific binding of non-polar analytes to the surfaces of various polymers has been previously reported in the literature (most notably for THC). ${ }^{20,27,33}$

\section{Matrix effect}

While matrix effects are mostly dependent on the selected LC-MS conditions, differences in observed matrix effects between samples collected with different sample collection swabs, but measured by the same analytical method, indicate that the presence of undesirable impurities may have played a role in the generation of matrix effects, resulting in signal enhancement or suppression in MS analysis.

The majority of the drug recovery results described in the Drug recovery paragraph (393 out of 735 (53.5\%)) does not seem to be significantly biased, as measured values of corresponding matrix effects were within the $80-120 \%$ range (see Table B3 in ESI B $\dagger$ ).

Among the tested substances, alprazolam and anastrozole were the least prone to matrix effects, as results obtained with all evaluated swabs fell within the aforementioned range. For betamethasone, nandrolone, and prednisone, only 1 adverse result was recorded. In contrast, results for phencyclidine were only unbiased with Dräger DCD ${ }^{\mathrm{TM}} 5000$ (97.8\%). Only 2 out of the 15 tested swabs yielded matrix effect values within the desired range (80-120\%) for each of the following compounds: clenbuterol (Porex® Saliva Collection Swab (type II) - 86.5\% and Sarstedt Salivette ${ }^{\circledR}$ Cortisol - 89.5\%), cocaine (Sarstedt Salivette ${ }^{\circledR}-106.9 \%$ and Oasis Diagnostics ${ }^{\circledR}$ Micro $\cdot S A L^{\mathrm{TM}}$ 96.2\%), methadone (Malvern Medical Developments Oracol $110.8 \%$ and Oasis Diagnostics ${ }^{\circledR}$ Micro·SAL ${ }^{\mathrm{TM}}-117.4 \%$ ), and 
metoprolol (Porex® Saliva Collection Swab (type II) - 92.9\% and Sarstedt Salivette ${ }^{\circledR}$ Cortisol - 99.0\%).

A total of 160 out of 735 results were below $80 \%$ - indicating signal suppression. Results below $80 \%$ were measured with 8 swabs for fenoterol, meldonium, propranolol, and zolpidem, and with as much as 9 swabs for LSD. No cases of signal suppression were present with the Oasis Diagnostics ${ }^{\circledR}$ Accu.SAL ${ }^{\mathrm{TM}}$. Only 1 such case occurred with the OraSure Technologies Intercept ${ }^{\circledR}$ i $2^{\mathrm{TM}}$, Immunalysis ${ }^{\mathrm{TM}}$ Quantisal ${ }^{\circledR}$ and StatSure $^{\mathrm{TM}}$ Saliva Sampler ${ }^{\mathrm{TM}}$.

On the other hand, 182 obtained results were over $120 \%$ suggesting signal enhancement. Elevated matrix effect values were registered with 10 of the 15 tested swabs for methadone and methylphenidate, 11 swabs for buprenorphine, 12 swabs for atenolol, and 13 swabs for phencyclidine. Only 2 such cases occurred with the Oasis Diagnostics ${ }^{\circledR}$ Micro·SAL ${ }^{\mathrm{TM}}$ and Malvern Medical Developments Oracol.

Nevertheless, the majority of results were within $80-120 \%$ for 8 out of 15 swabs. The greatest number of unbiased results was obtained with the Dräger DCD ${ }^{\mathrm{TM}} 5000$ (for 33 out of 49 analysed drugs). The remaining 7 swabs are Porex® Saliva Collection Swab (type II) (32/49), Porex® Saliva Collection Swab (type I) (31/49), Salimetrics ${ }^{\circledR}$ SalivaBio Oral Swab and Thermo Scientific $^{\mathrm{TM}}$ Oral-Eze ${ }^{\mathrm{TM}}$ (both 30/49), Sarstedt Salivette ${ }^{\circledR}$ Cortisol (29/49), Immunalysis ${ }^{\mathrm{TM}}$ Quantisal ${ }^{\circledR}$ (27/49), and StatSure $^{\text {TM }}$ Saliva Sampler ${ }^{\mathrm{TM}}(26 / 49)$.

\section{Assessment of matrix effect influence on the results}

Establishment of matrix effect values from sample collection swabs enables an assessment of corrected recovery values for each substance. For this purpose, following the methodology previously proposed by Matuszewski et al., ${ }^{34}$ the equation corrected drug recovery $[\%]=($ drug recovery $[\%] /$ matrix effect $[\%])$ $\times 100 \%$ was used to compute corrected recovery values.

While such approach results in only putative results, it is justified by a nearly 2 -fold decline in the number of suspiciously high recovery values - above 120\% (from 127 to 76 cases) and a 6-fold decline in especially peculiar cases of more than doubled recovery values (from 30 to just 5 cases). Among the 735 computed values, 5 cases contributed to less than $0.7 \%$ frequency within all corrected results. Corrected recovery values for each drug and each sample collection swab are presented in Table B4 in ESI B. $\dagger$

With respect to drug recovery results, after applying correction for matrix effects, 13 out of 15 swabs (instead of 7/15) provided results within the $80-120 \%$ range for more than half of the evaluated substances, although the greatest numbers of such results (36/49) were still achieved with the Porex® Saliva Collection Swab (type II) and Dräger DCD ${ }^{\mathrm{TM}} 5000$ (previously, 29/49 before correction).

It is also worth mentioning that matrix effects exceeding $200 \%$ after collection of samples with swab-based devices for some of the substances analysed in this research (e.g. buprenorphine, LSD, methadone, THC, and zolpidem) have already been reported in the literature, with matrix effect values as high as $3358 \%$ for THC (before IS correction). ${ }^{35}$

\section{Further discussion}

Recovery results from this research are mostly in agreement (within $\pm 20 \%$ of given value) with values previously reported in scientific literature. In total, 64 eligible results for 4 various swabs were found in 10 unique reports. All the corresponding results are listed in Table 2. It should be emphasized that a direct comparison is only possible for Malvern Medical Developments Oracol and Sarstedt Salivette ${ }$, while for the Immunalysis ${ }^{\mathrm{TM}}$ Quantisal ${ }^{\circledR}$ and StatSure $^{\mathrm{TM}}$ Saliva Sampler ${ }^{\mathrm{TM}}$ the substance recovery values could have been altered by this work not using dedicated extraction buffers. It is likely an explanation for poorer recovery of some analytes (like THC), and for weaker correlation between the results (especially for the StatSure ${ }^{\mathrm{TM}}$ Saliva Sampler ${ }^{\mathrm{TM}}$ ).

For the Malvern Medical Developments Oracol, the attained results are in compliance for 4 out of 6 common analytes after applying correction for matrix effects (and also for 4 out of 6 before that correction). ${ }^{27}$ The Pearson's correlation coefficient value is $r=0.66$ ( $r=0.73$ before correction), $n=5$.

For the Immunalysis ${ }^{\mathrm{TM}}$ Quantisal ${ }^{\mathrm{T}}$, results are compliant for 8 out of 9 substances (4/9 before correction). ${ }^{17,20,22,26,27,36}$ The correlation coefficient value is $r=0.59(r=0.43$ before correction), $n=20$.

With the StatSure ${ }^{\mathrm{TM}}$ Saliva Sampler ${ }^{\mathrm{TM}}, 4$ out 6 drugs have similar recovery values (3/6 before correction). ${ }^{26,27}$ The Pearson's coefficient value is $r=0.22(r=-0.19$ before correction), $n=6$.

The Sarstedt Salivette ${ }$, as the most thoroughly studied device, enabled a comparison of results for 12 drugs. Results were in agreement for 9 of them $(6 / 12$ before correction). ${ }^{2,12,27,37,38}$ The correlation coefficient is $r=0.56(r=$ 0.54 before correction), $n=21$.

\section{Influence of non-specific binding on the results}

Although non-specific binding of some especially non-polar analytes to surfaces of polymers used in this research was noted and described in the Non-specific binding of drugs to laboratory plastics paragraph, the issue affected only a marginal fraction of results and all of the 15 evaluated swabs were equally burdened by this phenomenon. Therefore, the recovery results were not corrected for its influence. However, this could partially explain lesser recovery values than previously reported for non-polar substances (particularly THC and THC-COOH). For example, if the THC recoveries would be corrected for the influence of the non-specific binding using an established value of $79.5 \%$ substance loss on the $15 \mathrm{~mL}$ Falcon tubes (as the analytes had the longest exposure time $(1 \mathrm{~h})$ with this particular type of plastic), the recovery values would increase from the $0.4-17.3 \%$ range (with a mean value of $6.9 \%$ and a median of $7.4 \%$ ) to the $1.8-84.4 \%$ range (with a mean value of $33.8 \%$ and a median of $36.3 \%$ ). Nonetheless, the differences between the swabs would still remain exactly proportional to the ones prior to such correction.

\section{Eligibility of testing recovery from swabs with ultrapure water}

The outcome of the follow-up experiment seems to reassure the relevance of results achieved with ultrapure water in 
Table 2 Comparison of substance recovery values [\%] from oral fluid collection devices established in this research with corresponding data previously reported in scientific literature

\begin{tabular}{|c|c|c|c|c|c|}
\hline Collection device & Substance & $\begin{array}{l}\text { Substance } \\
\text { recovery }\end{array}$ & $\begin{array}{l}\text { Recovery corrected for } \\
\text { matrix effect }\end{array}$ & $\begin{array}{l}\text { Previously reported } \\
\text { recovery }\end{array}$ & Source \\
\hline \multirow[t]{6}{*}{ Malvern Medical Developments Oracol } & Alprazolam & 22.3 & 24.3 & 19.2 & 27 \\
\hline & Amphetamine & 65.4 & 73.3 & 69.1 & 27 \\
\hline & Cocaine & 66.2 & 94.2 & 35.1 & 27 \\
\hline & MDMA & 31.5 & 54.1 & 52.0 & 27 \\
\hline & Morphine & 83.7 & 103.0 & 81.5 & 27 \\
\hline & THC & 0.4 & 0.3 & $<12.5$ & 27 \\
\hline \multirow[t]{26}{*}{ Immunalysis ${ }^{\mathrm{TM}}$ Quantisal ${ }^{\circledR}$} & Alprazolam & 91.3 & 96.9 & 111.0 & 27 \\
\hline & Amphetamine & 98.1 & 90.6 & 98 & 26 \\
\hline & & & & $94.2-96.9$ & 22 \\
\hline & & & & 89.7 & 27 \\
\hline & & & & $\geq 80$ & 36 \\
\hline & Cocaine & 230.7 & 130.3 & 97 & 26 \\
\hline & & & & $91.2-95.7$ & 22 \\
\hline & & & & 81.7 & 27 \\
\hline & & & & $\geq 80$ & 36 \\
\hline & Ketamine & 101.3 & 98.8 & $\geq 80$ & 36 \\
\hline & MDMA & 135.5 & 91.2 & 82.3 & 27 \\
\hline & & & & $<80$ & 36 \\
\hline & Methamphetamine & 135.3 & 96.5 & $93.1-103.8$ & 22 \\
\hline & & & & 100 & 26 \\
\hline & & & & $\geq 80$ & 36 \\
\hline & Morphine & 112.5 & 90.6 & 91.9-98.7 & 22 \\
\hline & & & & 98 & 26 \\
\hline & & & & 82.7 & 27 \\
\hline & & & & $\geq 80$ & 36 \\
\hline & $\mathrm{THC}$ & 9.9 & 6.7 & 94 & 26 \\
\hline & & & & $81.3-91.4$ & 22 \\
\hline & & & & 80 & 20 \\
\hline & & & & $75-85$ & 17 \\
\hline & & & & $48.7-67.5$ & 36 \\
\hline & & & & 55.8 & 27 \\
\hline & THC-COOH & 69.2 & 109.8 & 93 & 26 \\
\hline \multirow[t]{7}{*}{ StatSure ${ }^{\mathrm{TM}}$ Saliva Sampler ${ }^{\mathrm{TM}}$} & Alprazolam & 93.7 & 93.0 & 91.1 & 27 \\
\hline & Amphetamine & 97.2 & 85.5 & 88.7 & 27 \\
\hline & Cocaine & 232.3 & 135.5 & 85.6 & 27 \\
\hline & MDMA & 133.0 & 85.8 & 86.3 & 27 \\
\hline & Morphine & 103.8 & 88.4 & 88.5 & 27 \\
\hline & $\mathrm{THC}$ & 17.3 & 6.7 & 85.4 & 27 \\
\hline & & & & $>73$ & 17 \\
\hline \multirow[t]{25}{*}{ Sarstedt Salivette ${ }^{\circledR}$} & Alprazolam & 85.3 & 91.3 & 27.3 & 27 \\
\hline & Amphetamine & 71.8 & 94.4 & $85.63-86.07$ & 12 \\
\hline & & & & $54-57$ & 2 \\
\hline & & & & 51.8 & 27 \\
\hline & Buprenorphine & 58.0 & 44.9 & $20.2-21.7$ & 37 \\
\hline & Cocaine & 108.1 & 101.1 & $91-92$ & 2 \\
\hline & & & & $90.84-91.56$ & 12 \\
\hline & & & & $81.7-91.4$ & 38 \\
\hline & & & & $>73.3$ & 37 \\
\hline & & & & 33.3 & 27 \\
\hline & Heroin & 100.0 & 87.4 & $79.2-85.2$ & 38 \\
\hline & & & & $>73.3$ & 37 \\
\hline & MDMA & 71.9 & 80.3 & 26.5 & 27 \\
\hline & Methadone & 69.6 & 51.0 & $47.4-50.8$ & 37 \\
\hline & Methamphetamine & 110.3 & 97.8 & $87.97-88.81$ & 12 \\
\hline & & & & $55-59$ & 2 \\
\hline & Morphine & 99.4 & 72.4 & $78.46-81.63$ & 12 \\
\hline & & & & $73.9-78.3$ & 38 \\
\hline & & & & $>73.3$ & 37 \\
\hline & & & & $38-46$ & 2 \\
\hline & & & & 35.2 & 27 \\
\hline & Phencyclidine & 195.6 & 99.4 & $76.34-81.71$ & 12 \\
\hline & THC & 5.7 & 7.1 & $<12.5$ & 27 \\
\hline & THC-COOH & 7.3 & 8.7 & $12.17-47.41$ & 12 \\
\hline & & & & $12-47$ & 2 \\
\hline
\end{tabular}


accordance with testing oral fluid samples. Recovery values measured using both matrices are similar for tested swabs, and there is a strong positive correlation between both datasets (Pearson's correlation coefficient value is $r=0.73, n=43$ ). Less than a quarter of compared pairs (oral fluid $v s$. water) differ by more than $20 \%$. On average, recoveries were $5.8 \%$ greater from the oral fluid, than from water (median of $7.0 \%$ ), and that small difference was likely caused by the use of an extraction method, which was necessitated for testing biological matrices. Impact of the sample preparation process on the final result is commonly acknowledged. ${ }^{39}$ And as was aptly concluded by majors: Sample processing typically accounts for at least one-third of the error generated. ${ }^{40}$ RSD values are also higher with oral fluid samples (average of 5.1\%, and median of $3.4 \%$ ). Increased variation of the results was expected for biological matrices, as this was the main rationale behind using ultrapure water for the main evaluation of the swabs. Full results of this comparison are presented in Table B5 in ESI B. $\dagger$

\section{Conclusions}

The choice of an adequate oral fluid sample collection method is critical to the attainment of representative results, as certain methods can enormously influence analyte concentrations. Differences in analyte recovery values as great as 100 fold between samples collected with different collection swab types were observed in this research. Yet, this issue seems to be massively underrecognized and underappreciated. Many researchers tend to prioritize improving existing sample preparation and analysis methods, while many difficulties could be easily avoided by focusing attention on obtaining samples of superior quality - with emphasis placed on the sample collection step. This paper aims to initiate further discussion on this subject. Furthermore, the disclosed findings could be of substantial aid in the selection of an appropriate oral fluid sample collection method for HPLC-MS/MS analysis of 49 widespread drugs of abuse and doping agents.

\section{Conflicts of interest}

There are no conflicts to declare.

\section{Acknowledgements}

This work was supported by The National Centre for Research and Development under Lider IX programme (grant LIDER/44/ 0164/L-9/17/NCBR/2018).

The authors would like to thank Department of Pharmacodynamics and Molecular Pharmacology, Faculty of Pharmacy, Collegium Medicum in Bydgoszcz at Nicolaus Copernicus University in Torun, Poland for access to the Shimadzu LCMS-8060 instrument, Shim-Pol A.M. Borzymowski for technical assistance, and Bartosz Sadowski for his help during the experimental part of this work (experiments described in Drug recovery and Non-specific binding of drugs to laboratory plastics paragraphs).

Permission to conduct experiments with oral fluid was issued by the Bioethics Committee of Collegium Medicum in Bydgoszcz at Nicolaus Copernicus University in Torun (permission number KB 651/2018), and permission to work with controlled substances was issued by the local Pharmaceutical Inspector (Kujawsko-Pomorski Wojewódzki Inspektor Farmaceutyczny w Bydgoszczy, permission number WIFBY-KK.857.2.4.2016).

\section{Notes and references}

1 J. K. M. Aps and L. C. Martens, Review: The physiology of saliva and transfer of drugs into saliva, Forensic Sci. Int., 2005, 150(2-3), 119-131, DOI: 10.1016/j. forsciint.2004.10.026.

2 D. J. Crouch, Oral fluid collection: the neglected variable in oral fluid testing, Forensic Sci. Int., 2005, 150(2-3), 165-173, DOI: 10.1016/j.forsciint.2005.02.028.

3 S. Anizan and M. A. Huestis, The Potential Role of Oral Fluid in Antidoping Testing, Clin. Chem., 2014, 60(2), 307322, DOI: 10.1373/clinchem.2013.209676.

4 V. Reinstadler, S. Lierheimer, M. Boettcher and H. Oberacher, A validated workflow for drug detection in oral fluid by non-targeted liquid chromatography-tandem mass spectrometry, Anal. Bioanal. Chem., 2019, 411(4), 867876, DOI: 10.1007/s00216-018-1504-x.

$5 \mathrm{H}$. Elmongy and M. Abdel-Rehima, Saliva as an alternative specimen to plasma for drug bioanalysis: A review, TrAC, Trends Anal. Chem., 2016, 83 part B, 70-79, DOI: 10.1016/j. trac.2016.07.010.

6 M. Gröschl, Saliva: a reliable sample matrix in bioanalytics, Bioanalysis, 2017, 9(8), 655-668, DOI: 10.4155/bio-20170010.

7 V. Vindenes, H. M. E. Lund, W. Andresen, H. Gjerde, S. E. Ikdahl, A. S. Christophersen and E. L. Øiestad, Detection of drugs of abuse in simultaneously collected oral fluid, urine and blood from Norwegian drug drivers, Forensic Sci. Int., 2012, 219(1-3), 165-171, DOI: 10.1016/j. forsciint.2012.01.001.

8 H. Gjerde, K. Langel, D. Favretto and A. G. Verstraete, Detection of illicit drugs in oral fluid from drivers as biomarker for drugs in blood, Forensic Sci. Int., 2015, 256, 4245, DOI: 10.1016/j.forsciint.2015.06.027.

9 J.Á. Lema-Atán, A. de Castro, E. Lendoiro, M. LópezRivadulla and A. Cruz, Toxicological oral fluid results among Spanish drivers testing positive on on-site drug controls from 2013 to 2015, Drug Alcohol Depend., 2019, 195, 106-113, DOI: 10.1016/j.drugalcdep.2018.12.003.

10 K. Goryński, A critical review of solid-phase microextraction applied in drugs of abuse determinations and potential applications for targeted doping testing, TrAC, Trends Anal. Chem., 2019, 112, 135-146, DOI: 10.1016/j.trac.2018.12.029. 
11 V. Bessonneau, E. Boyaci, M. Maciazek-Jurczyk and J. Pawliszyn, In vivo solid phase microextraction sampling of human saliva for non-invasive and on-site monitoring, Anal. Chim. Acta, 2015, 856, 35-45, DOI: 10.1016/j. aca.2014.11.029.

12 D. J. Crouch, J. Day, J. Baudys and A. A. Fatah, Evaluation of Saliva/Oral Fluid as an Alternate Drug Testing Specimen, National Institute of Standards and Technology (NIST), Gaithersburg, MD, 2004.

13 C. A. MacCall, G. Ritchie and M. Sood, Oral fluid testing as an alternative to urine testing for drugs of abuse in inpatient forensic settings: giving patients choice, Scott. Med. J., 2013, 58(2), 99-103, DOI: 10.1177/0036933013482640.

14 M. Dhima, T. J. Salinas, R. A. Wermers, A. L. Weaver and S. Koka, Preference changes of adult outpatients for giving saliva, urine and blood for clinical testing after actual sample collection, J. Prosthodont. Res., 2013, 57(1), 51-56, DOI: 10.1016/j.jpor.2012.09.004.

15 H. Teixeira, P. Proença, A. Verstraete, F. Corte-Real and D. N. Vieira, Analysis of Delta9-tetrahydrocannabinol in Oral Fluid Samples Using Solid-Phase Extraction and HighPerformance Liquid Chromatography-Electrospray Ionization Mass Spectrometry, Forensic Sci. Int., 2005, 150(2-3), 205-211, DOI: 10.1016/j.forsciint.2004.11.026.

16 G. F. Kauert, S. Iwersen-Bergmann and S. W. Toennes, Assay of Delta9-tetrahydrocannabinol (THC) in Oral FluidEvaluation of the OraSure Oral Specimen Collection Device, J. Anal. Toxicol., 2006, 30(4), 274-477, DOI: 10.1093/jat/ 30.4.274.

17 S. M. R. Wille, V. Di Fazio, M. d. M. Ramírez-Fernandez, N. Kummer and N. Samyn, Driving Under the Influence of Cannabis: Pitfalls, Validation, and Quality Control of a UPLC-MS/MS Method for the Quantification of Tetrahydrocannabinol in Oral Fluid Collected With StatSure, Quantisal, or Certus Collector, Ther. Drug Monit., 2013, 35(1), 101-111, DOI: 10.1097/ FTD.0b013e318278dbe4.

18 R. Mullangi, S. Agrawal and N. R. Srinivas, Measurement of xenobiotics in saliva: is saliva an attractive alternative matrix? Case studies and analytical perspectives, Biomed. Chromatogr., 2009, 23(1), 3-25, DOI: 10.1002/bmc.1103.

19 M. F. Keil, Salivary cortisol: a tool for biobehavioral research in children, J. Pediatr. Nurs., 2012, 27(3), 287-289, DOI: 10.1016/j.pedn.2012.02.003.

20 C. Moore, M. Vincent, S. Rana, C. Coulter, A. Agrawal and J. Soares, Stability of Delta(9)-tetrahydrocannabinol (THC) in oral fluid using the Quantisal collection device, Forensic Sci. Int., 2006, 164(2-3), 126-130, DOI: 10.1016/j. forsciint.2005.12.011.

21 S. Dickson, A. Park, S. Nolan, S. Kenworthy, C. Nicholson, J. Midgley, R. Pinfold and S. Hampton, The recovery of illicit drugs from oral fluid sampling devices, Forensic Sci. Int. $\quad 2006, \quad$ 165(1), 78-84, DOI: 10.1016/j. forsciint.2006.03.004.

22 O. Quintela, D. J. Crouch and D. M. Andrenyak, Recovery of drugs of abuse from the Immunalysis Quantisal oral fluid collection device, J. Anal. Toxicol., 2006, 30(8), 614-616, DOI: $10.1093 /$ jat $/ 30.8 .614$.

23 M. Gröschl, H. Köhler, H. G. Topf, T. Rupprecht and M. Rauh, Evaluation of saliva collection devices for the analysis of steroids, peptides and therapeutic drugs, J. Pharm. Biomed. Anal., 2008, 47(3), 478-486, DOI: 10.1016/j. jpba.2008.01.033.

24 A. J. Hall, J. V. Warner, M. G. Henman and W. E. Ferguson, Recovery of drugs of abuse from Dräger DCD5000 oral fluid collection device in Australia, J. Anal. Toxicol., 2015, 39(2), 140-143, DOI: 10.1093/jat/bku123.

25 K. L. Samano, L. Anne, T. Johnson, K. Tang and R. H. B. Sample, Recovery and Stability of $\Delta 9$ Tetrahydrocannabinol Using the Oral-Eze® Oral Fluid Collection System and Intercept ${ }^{\circledR}$ Oral Specimen Collection Device, J. Anal. Toxicol., 2015, 39(8), 648-654, DOI: 10.1093/ jat/bkv093.

26 C. Cohier, B. Mégarbane and O. Roussel, Illicit Drugs in Oral Fluid: Evaluation of Two Collection Devices, J. Anal. Toxicol., 2017, 41(1), 71-76, DOI: 10.1093/jat/bkw100.

27 K. Langel, C. Engblom, A. Pehrsson, T. Gunnar, K. Ariniemi and P. Lillsunde, Drug testing in oral fluidevaluation of sample collection devices, J. Anal. Toxicol., 2008, 32(6), 393-401, DOI: 10.1093/jat/32.6.393.

28 European Drug Report 2019: Trends and Developments, http://www.emcdda.europa.eu/publications/edr/trends-developments/2019_en, (accessed April 30, 2020).

292018 Anti-Doping Testing Figures, https://www.wada-ama. org/en/resources/laboratories/anti-doping-testing-figuresreport, (accessed April 30, 2020).

302020 Prohibited List, https:/www.wada-ama.org/en/ resources/science-medicine/prohibited-list-documents, (accessed April 30, 2020).

31 F. G. Bellagambi, T. Lomonaco, P. Salvo, F. Vivaldi, M. Hangouët, S. Ghimenti, D. Biagini, F. Di Francesco, R. Fuoco and A. Errachida, Saliva sampling: Methods and devices. An overview, TrAC, Trends Anal. Chem., 2020, 124, 115781, DOI: 10.1016/j.trac.2019.115781.

32 PubChem database, https:/pubchem.ncbi.nlm.nih.gov/, (accessed April 30, 2020).

33 A. Molnar, J. Lewis and S. Fu, Recovery of spiked $\Delta 9$-tetrahydrocannabinol in oral fluid from polypropylene containers, Forensic Sci. Int., 2013, 227(1-3), 69-73, DOI: 10.1016/j. forsciint.2012.11.006.

34 B. K. Matuszewski, M. L. Constanzer and C. M. Chavez-Eng, Strategies for the assessment of matrix effect in quantitative bioanalytical methods based on HPLC-MS/MS, Anal. Chem., 2003, 75(13), 3019-3030, DOI: 10.1021/ac020361s.

35 H. M. Lund, E. L. Øiestad, H. Gjerde and A. S. Christophersen, Drugs of abuse in oral fluid collected by two different sample kits - stability testing and validation using ultra performance tandem mass spectrometry analysis, J. Chromatogr. B: Biomed. Sci. Appl., 2011, 879(30), 3367-3377, DOI: 10.1016/j.jchromb.2011.09.002.

36 M. H. Y. Tang, C. K. Ching, S. Poon, S. S. S. Chan, W. Y. Ng, M. Lam, C. K. Wong, R. Pao, A. Lau and T. W. L. Mak, 
Evaluation of three rapid oral fluid test devices on the screening of multiple drugs of abuse including ketamine, Forensic Sci. Int., 2018, 286, 113-120, DOI: 10.1016/j. forsciint.2018.03.004.

37 M. Concheiro, T. R. Gray, D. M. Shakleya and M. A. Huestis, High-throughput simultaneous analysis of buprenorphine, methadone, cocaine, opiates, nicotine, and metabolites in oral fluid by liquid chromatography tandem mass spectrometry, Anal. Bioanal. Chem., 2010, 398(2), 915924, DOI: 10.1007/s00216-010-3903-5.
38 R. Dams, R. E. Chooa, W. E. Lambert, H. Jones and M. A. Huestis, Oral fluid as an alternative matrix to monitor opiate and cocaine use in substance-abuse treatment patients, Drug Alcohol Depend., 2007, 87(2-3), 258267, DOI: 10.1016/j.drugalcdep.2006.08.020.

39 V. R. Meyer and R. E. Majors, Minimizing the effect of sample preparation on measurement uncertainty, $L C G C$, 2002, 20(2), 106-112.

40 R. E. Majors, Overview of Sample Preparation, $L C G C, 1991$, 9(1), 16-20. 